\title{
Harmonious Coexistence: Multi-values of Prison Environment Color Design to Prisoners' Psychological Treatment*
}

\author{
Daoyi Wu \\ School of Art and Media \\ Hefei Normal University \\ Hefei, China 230601
}

\begin{abstract}
As the construction of a harmonious society is going, the construction pattern of prison is being adjusted rapidly accordingly. The value of modern prison is mainly embodied in two aspects: imprisonment and transformation. Along with the development of human civilization and social legal system, the transforming function of prison has been paid more and more attention to. Environment color design is one of the most important parts that develop both physical and spiritual forms of prison. Its irreplaceable effect on prisoners' psychological treatment makes it an indispensable part of the treatment. The paper reviews foreign and domestic theories of prison's environmental planning and construction and bases its thesis on chromatics and environmental metaphysics. It firstly introduces theoretical principle and technology of prisoners' psychological treatment and other theories like prison environment design. Then the paper teases out scientific classification of prison environment and subordinate position of colors, confirms the effects that prison's environment color design has on prisoners' psychological treatment, identifies functional areas of prison and multiple positive effects from beautification of overall prison environment. In this way, it elaborates that prison's environment color design, with treating, channeling, inspiring, balancing, regulating or identifying effects, meets the demand of prisoner's psychological treatment and becomes an effective treatment.
\end{abstract}

Keywords-prisoner; environment color design; psychological treatment; functional effects

\section{INTRODUCTION}

According to a famous sociologist Mr. Fei Xiaotong, "social research should start from prison because prison is the best sample to study social history and culture." [1] In China, Prison Law states that prison should follow the principle of combining punishment with transformation, education with labor and transform prisoners into lawabiding citizens. Since Reform and Opening-up, prison has taken an active action to improve its transformation-focused function, to overcome institutional barriers, to update prison police's work skills and to utilize modern scientific

*Fund project: China's Ministry of Education Humanities and Social Science Research Fund for Youth, 2014. (Project Name: Research on the Prison's Environment Color Deign in a Harmonious Society, Project Number: 14YJC760064). achievements. By all these means, it aims to raise prison's management and educational level and to improve the efficiency of law enforcement, so as to lead China's prison system of punishment and environmental construction to a more humanized direction. With the construction of $21 \mathrm{st}$ century China's spiritual civilization, and the implementation of psychological treatment in prison, many experts and scholars are determined to prisoners' psychological research. Combined with domestic and foreign experience of prisoners' transformation, they try to work out some effective ways to help prisoners' psychological treatment. The effect that the prison environment color design has on prisoners' psychological treatment has imperceptibly influenced prisoners and achieved its psychological treatment function without their notice. By vigor research and construction of prison environment, it can not only improve the quality of penalty execution, reduce the cost of penalty execution and optimize the resources in prison, but also enhance the effectiveness and positive effect of prison environment to prisoners' psychological treatment, which promote the scientificalness, systematicness and humanism of the treatment [2]. Nowadays, as the development of China's construction of a harmonious society, the institutionalization, scientificalization and socialization of prison work have been propelled. It has been more and more widely recognized by theorists and governors of prison that jail is no longer an impalpable part of the society. In China, there are a lot of research works and practical cases related to construction color, environment color and visual image. But research on the relationship between prison's environment color design and prisoners' transformation is relatively insufficient, especially that the research on the effectiveness of the environment color design to prisoners' psychological treatment is still in the initial stage.

\section{CURRENT SITUATION OF DOMESTIC AND FOREIGN} PRISON ENVIRONMENT PLANNING AND CONSTRUCTION

The planning and construction of prison environment has not formed a systematic theoretical system in China and it is only at the beginning stage. In 1990, the Ministry of Justice promulgated Regulatory Specification of Environment Reform. It clearly defines regulation and guard installations, 
production area, learning zone and living quarter of prisoner as the objectives of regulatory environment reform. Reasonable planning, security guarantee, being conducive to regulation and convenient to living is required to the reform. The layout shall be reasonable with scientific and standardized construction, and the environment of cell, classroom and prison shall be clean and tidy, while the workshop and work place shall be organized. In 2002, the Ministry of Justice implemented Prison Construction Standard. It aims to increase the accuracy of execution of punishment, prevent and decrease crime and put forward a single standard for prison construction to ensure a scientific and standardized construction. This is the first time that the prison construction and the objectives of execution of punishments are unified, giving both punishment and transformation functions to the physical environment of prison. Also, it is the first time to propose a single standard for prison construction and clear its principle, which meets the needs of prison administration security and transformation of prisoners. It is an important symbol of the transformation function of prison's environment construction. At present, the environment offered by the civilized prison, garden prison and open prison in domestic developed cities is a specific reflection of the humanized prison, which is also important for us to be in line with western civilized prison standard.

Modern western practices of prisoners' transformation mainly include educational transformation, psychological transformation, social transformation and religious transformation. Many scholars, researchers, regulatory agencies and other related parties have done theoretical research on the transformation methods, and the research on the transformation function of prison environment goes relatively deeper. In 19 th century, the center of western prison improvement movement transferred from Europe to the United States. Researches on the transformation system, "Living Alone" and "Muteness" put forward new ideas for the prison building construction and environmental design. Consequently, various styles of prison building and environment were constructed and formed, making prison more adjusted to prisoners' psychological treatment and behavior needs [3]. While the international community and governments are in the fight against crime, they are also committed to safeguarding the rights of prisoners and effectively transforming prisoners. Some areas have also constituted regional regulations which are higher than the standard of United Nations Minimum Standard of the Treatment of Prisoners. For example, in the United States, France, Britain, Sweden, Holland, Norway, Japan and other countries, they have carried out researches on how to combine prison environment design with the idea of execution of punishment and transformation, and the system of execution. However, there are relatively fewer discussions on typical cases of the prison environment color design and prisoners' psychological treatment.

\section{ClassificAtion OF PRISON ENVIRONMENT AND SUBORDINATE POSITION OF COLORS}

Based on the analysis of the existing literature and the research of scholars, there are various division standards for the prison environment. Some governors divide prison environment into prisoners' sentence serving environment and prison police' working environment; some scholars divide it into physical environment and psychological environment; and some researchers classify it into "hard environment" and "soft environment". The environment of prison is very important. This paper focuses on the prison environment's classification of material and spiritual levels, which are mainly embodied in the "hard environment" (tangible material situation) and "soft environment" (invisible spiritual situation). Hard environment refers to the hardware environment, also hardware facilities. It mainly includes all needed material and tangible conditions needed by the prison activities, such as labor environment, management environment, educational environment, cultural environment, board and lodging environment. If given specific examples there are cells, counseling rooms, classrooms, meeting rooms, dining rooms, work places, catharsis room, library, theaters, exhibition halls, newspaper boards, sports venues and the like. Soft environment refers to the software environment, also software facilities. It mainly indicates all varieties of non-material and intangible conditions of the prison activities, which may include law enforcement environment, humanity environment, spiritual environment, psychological atmosphere, rules and regulations and so on [4]. This paper focuses on the reform of prison environment. The hard environment includes regulatory environment, working environment, educational environment, culture environment, hygienic conditions, board and lodging environment and so on. The soft environment includes law enforcement environment, humanity environment, spiritual environment, etc. Among these two kinds of environment, the soft environment has innovative effect on the transformation method, such as psychological treatment, prison culture and community education and help.

Prison environment is a manifestation of prison's materialized form and its value is dominated by the prison cultural orientation. Its plan and construction can use artistic elements contained in prison culture connotation, like color, image, carrier, symbol and model, which is helpful to the improvement of prison culture construction. At present, the core values of the prison culture are to improve quality of prisoners' correction, to reduce rate of crime, and to help keep social harmony and stability. Therefore, under the premise of ensuring supervision and management security, prison environment should meet the needs of prisoners' correction. It is precisely because of the pursuit of the cultural value of the prison, the color design of the prison environment fully embodies the concept of cultural values, which makes the need of prisoners' psychological treatment has become an important part of it. The concept of the prison education reform accelerates the formation of environmental transformation theory. New developing scientific prisoners' recognizing and transforming methods, such as 
psychological treatment, prison culture, community education and help, community rectification, have been perfecting the transformation function and the method of the prison environment [5]. All punishment activities are carried out under the prison environment. Since the prison environment consists of soft and hard environment, each environment has different functional requirements and the configuration and function of each environmental color design is different as well. It exerts different effects on the mentality and behaviors of prisoners. The relation between psychological treatment and functions of the prison's environment color design, like control function, punishment function, transformation function and the maintenance function, have provided an integrated service basis for the prisoners' psychological treatment.

\section{MULTI-FUNCTIONS OF PRISON's ENVIRONMENT COLOR DESIGN}

Color design in prison is the manifestation of the prison environment construction, and also an effective carrier of the special function of prison. To study and improve prison environment undoubtedly can help exert the transformation function of the prison. The prison's environment color design has its existence value because it not only reflects the characteristics of imprisonment, but also embodies the connotation of correction; it not only reflects the civilization and progress of the society, but also embodies combination of the regional culture and the local environment. Color is essential to human beings. It affects the living environment of human. It gives human some biological significance and at the same time helps human brain produce a more sensible interpretation of everyday things. In other words, color is important in the aspect of enriching and changing the quality of life. Prison's environment color configuration, as the reflection of human subjective activities, mainly involves subjective perception of the designer and the creative artificial color environment construction. Meanwhile, according to mental association, abstract symbolism, emotional experience, space perception and other characteristics of color, when it comes to prison environment construction and color configuration, it should give full consideration into the psychological effect different colors have on the prisoners. In this way, the quality of transformation can be improved.

\section{A. Psychology of Prisoners}

Color is one of the important components of design aesthetics, and it is also an important factor in art of environmental. It not only meets the needs of people and material function, but also carries some aesthetic and spiritual functions. The choice and application of the prison environment color, besides adapting to the structural features of the overall environment and inner space of the prison, shall also meet the psychological and physiological needs of the prisoners, and indirectly eliminate unsafe factors inside the prison. At present, the use of color in prison construction area is extremely active, and its performance is becoming more and more remarkable and rich. Prisoners who have stayed a long time in limited prison environment have differences in psychological and emotional reactions and color perception. Therefore, attentions should be paid to the matching and reconciliation of environment color design so as to create a comfortable and effective color space to reduce the tension of the prison atmosphere and to regulate the emotions of the prisoners. In this way, prisoners get a fresh, quiet and comfortable feeling, which will cultivate prisoners' characters and inject some vitality to their psychological correction. For example, a prison in Holland boldly uses the color gradient technique in its cells. Each prison house's public space is painted in different colors, forming a series of change in order. The color sky blue, light blue, light red and other bright colors are used, and colors that are too sharp, depressing are avoided. Other parts of the prison house use unified white material, which shows the pursuit of local changes in the overall environment, creating a harmonious effect [6].

\section{B. Identify Prison's Functional Areas}

The prison's environment color design should be in coordination with the purposes and functions of different areas, to strengthen and distinguish the uses and functions of the external and internal space of the prison house and facilities, making it clear to identify various functions of different areas in prison. Although the use of many functional areas is not unchanged, now people pay more attention to the color decoration of these functional areas. For example, the prison administrative office color design should choose a sedate, elegant, majestic monochrome, of which the color purity should not be too high and the visual texture of the material should be in a regular and ordered change. On the other hand, the color of the policeman's gym should be in high saturation, stimulating people's enthusiasm and arousing people's longings. Take a women's prison in Hebei province for another example. Within the walls, its prison houses, teaching buildings, meeting buildings, workshops, and prisoners' canteen are all in pink, light blue and other colors with soft tones, so as to ease mental depression of the prisoners. The gate of the prison is silver, and the exterior walls are purple, showing the grave and dignified bearing of the prison. In the construction of the prison environment, the most mental-influential places to prisoners are prison houses and workshops. Most of escape, quarrel and fight, suicide, murder and other actions undermining supervision occur in these two places. In workshops, the indoor color should be full of beauty and delight, so as to reduce sense of boredom from everyday simple and repeated work and thereby enhancing the working enthusiasm of prisoners [7].

\section{Beautify the Overall Prison Environment}

People, who live around color for a long time, gradually get interested in colors, and their aesthetic consciousness of color emerges. As we now live in a world full of colors and the level of our spirits and living standard is raising up, people not only pursue a reasonable application standard of color, but also pay attention to its need of beautification. The art of color has become an important part of people's live and the science of color also has penetrated into every field of our life and production. The construction of prison 
environment is for prisoners and police, to meet their needs of space for basic necessities of life. Since all environment colors are designed around it, the question that how to build a harmonious living environment is raised. The key to it is to achieve an overall coordination and change in the environment through a reasonable color matching. The prison's environment color design should exert its beautification effect and have its own prison style. A successful prison environment design should not only have a creative style, but also give people a sense of beauty. In terms of a single prison building, it should take its interplay with the surroundings into consideration, also the coordination with nearby natural environment and needs for cultural connotation. Otherwise, it not only damages nearby natural environment, but also has negative effect on the prisoners' psychological treatment. For example, exterior walls of foreign remand home are colored in light blue fluorocarbon paint, which is coordinated with the entire surrounding environment and also beautify the prison environment.

\section{VALUES OF PRISON'S ENVIRONMENT COLOR DESIGN IN THE PSYCHOLOGICAL TREATMENT OF PRISONERS}

At present, the research of penology is extended to the study of prison laws and regulations, buildings, management, prison staffs, psychology of prisoners, transformation and so on. It makes penology a rather inclusive subject. However, study of environmental color planning is still at very first stage with much room for improvement. Domestic prison designers focus more on the study of personalized characteristics formation and some specialized functions of the prison environment, while giving less time in the research on the influence of environment color on the prisoners' mentality and adjustment. Prisoners' psychological treatment includes supervision, education, labor and other methods, which all can be effectively carried out in certain prison environment. Through the comprehensive utilization of the supervision system, transformation form, education content of prison environment, the quality of the penalty and punishment can be improved. During the construction of modern human-oriented prison, the effect of color elements in the prison environment on prisoners' psychological treatment cannot be ignored. Its therapy, counsel, balance, encouragement, regulation and recognition effects would become indispensable factors of future prison's transformation technology.

\section{A. The Therapeutic Effect of Environment Color}

Thousands of years ago, the basic method of color therapy has been known. China's medical treatment has also adopted traditional color enhancement therapy. The basic principle of color therapy is that the energy of different parts of human body can be stimulated by being exposed to different colors. Similarly, the configuration of environment color has unexpected effects on the psychological, physical and mental rehabilitation of prisoners as well as on other transformation functions. Modern medical research has proved that red is stimulating and uplifting. It injects vitality into human body, and turn blood circulation and sensory more active. Therefore, red color can be used to treat visual, auditory, gustatory, tactile, olfactory problems and other symptoms. Orange can accelerate metabolism, promote digestion, stimulate sexual desire, and activate motor cells of the body. Therefore, orange color can provide a happy and satisfying feeling for people. Yellow can provide energy for muscle system, nervous system and brain. It promotes and purify the blood and lymphatic system, and has the power of psychological suggestion to the body, which can help produce a cheerful and positive attitude. Green promotes the growth of bones and muscles, helps release stress and stables the emotion. It gives a quiet, peaceful and comfortable feeling to people. Green is a natural nutrition. Blue is calm. It can reduce organ inflammation and relieve emotional impulse to help people relax. Purple nourishes and purifies blood, promotes the function of spleen, and contributes to the bone growth. White is a symbol of pure. It promotes the drops of high blood pressure and adjusts people's mood and mental state [8]. There are various means of environment color treatment, but there are with one ultimate goal is to improve both body and mind of related personnel. As for prisoners, the environment color treatment is important because it can play a part in the prisoners' psychological treatment when applied to different functional space and places.

\section{B. Psychological Counseling Effect of Environment Color}

Prison environment and prisoners are in special physical and mental state of the society. When prisoners experience beautiful color environment, their irritable mood can be dispersed. Prisoners' visual attention is being transferred by the atmosphere of the environment color, and that is when environment color plays a role in psychological counseling of the prisoners. Negative color environment can cause psychological changes of prisoners, which may lead to bad mood, thus affecting the psychological correction of prisoners. On the other hand, interestingly, pleasant color environment will stimulate positive emotions, conducive to the transformation and resocialization of prisoners. The image of the object comes into our mind when we often think of it in the heart. Some have a clearer image while some's is vague or nothing, but there is another way to reflect on the subject. Therefore, in the prison environment color design, prisoners can directly experience one or a variety of colors, having different feelings from different colors. Being surrounded by colors, prisoners will associate it with many beautiful pictures, just like a wonderful journey. This is a strong counseling power that colors have to prisoners. When prisoners experience beautiful color images in different environment in prison, it would promote their yearning for a better life. It offers physical and mental pleasure to prisoners and also a good psychological counselling, which is helpful to their psychological treatment.

\section{Psychological Inspiring Effect of Environment Color}

American psychologist Karl Rogers believes that people have the potential to understand themselves, to grow mature and to produce constructive change. The task of psychological treatment is to arouse this potential and promote it toward a healthy direction, rather than acting on 
their behalf to explain and guide it. He proposed a "people are constructive" concept, that the basic attribute of people is constructive and can be trusted. Solving conflicts between people should not with the attitude of psychological defense; instead it should be with a positive, progressive and constructive attitude. In the process of psychological treatment of prisoners, the potential of prisoners can be stimulated on the basis of the principles above, and it can encourage some positive psychological changes of prisoners. It is unavoidable for prisoners to have conflicts between others in different functional areas for being kept in a tense prison environment. Through matching different functional areas with color system, the inspiring effect of color can have a positive influence on the balance of prisoners' body and mind so as to lead the psychological health of prisoners to a healthy direction [9]. The ratio, quantity, and the balance or contrast between cold and warm of the color collocation has a stimulating effect on kinesthesia of prisoners, so that the various functions can be in healthy operation to form an effective transformation effect. The visual guidance function of color can provide a clear direction for the different areas of the prison and satisfy different psychological needs of prisoners, which makes prisoners get inspired and cheered up, so that they would produce a positive psychological desire.

\section{Psychological Balancing Effect of Environment Color}

Human being is a kind of organism, which is open to all kinds of relations with the people nearby. Also, there is a continuous exchange of material, energy and information within each system of human body and also between human and their surrounding environment. The psychological treatments for prisoners are varied, but with one single purpose is to solve their psychological block, to reduce their anxiety, depression, panic or other psychological symptoms, to change their non-adaptive behavior, so that they can make things straight through an appropriate way. According to Brummer [10], a contemporary American visual art psychologist, color evokes emotions, express feelings, and even affects our normal physiological experience. Positive color can cultivate prisoners' characters, appease their moods, and arouse their sense of justice and gumption, bringing them the vitality during the treatment. For example, based on the women's aesthetic psychological characteristics, using different colors to create an atmosphere of rich prison culture caters to their interests. For prisoners who are old and weak, the construction can use yellow, orange and other warm colors. Because the valetudinarian can be in a better mood and also get their metabolism and disease-resistance ability enhanced if they stay in such a color environment for a long time. According to the study of color psychology, green plants in nature can not only ease fatigue, but also increase the sensitivity of thinking. Therefore, it is beneficial to the balance of the ecological environment in prison if prison pay attention to greening.

\section{E. Psychological Regulating Effect of Environment Color}

Utilizing the regulating effect prison environment color to carry out prisoners' psychological treatment can gradually improve prisoners' self-regulating ability, help them cultivate a firm, tenacious, optimistic, cheerful and healthy personality, improve their adaptability and enhance their consciousness to correct bad habits and the persistence to overcome difficulties, so as to achieve the purpose of selfeducation. The physiological characteristics of human gives people the perception of color. The color design in prison environment utilizes the regulating function of color to the prisoners themselves, which makes it different from the labor reform and education reform. This environment reform can avoid negative factors brought by nervous emotion and body fatigue. Feeling the material space environment through colors in different prison areas, the prisoners can meet the need of living and transformation. It can furthest eliminate bad psychology of prisoners as well as unstable factors in prison, which is important to the construction of a harmonious prison. Director of the American Institute for Biological Research in Tacoma, Washington, Alexander Haworth found [11] that pink can effectively curb the violence in the United States. This theory has been confirming by the test result from the confinement of Seattle Navy, Youth Authority prisons of San Bernardino, California and veteran's hospital psychiatric ward in Los Angeles.

\section{F. Psychological Identifying Effect of Environment Color}

Color plays an important role in our visual perception. $80 \%$ of our perception comes from eyes, which makes vison as a perception with first advantage. The prison environment is a general term for prison construction, relevant facilities and places. Buildings and facilities in different environments have different uses and features. The prison building is a comprehensive concept and the environment color is mainly on the following three kinds of building. Firstly, housing, including prison cells, houses for police and armed police, and other housing buildings. Secondly, relevant facilities, like safety warning facilities, office establishment for cadres and policeman, living, education and transformation facilities for prisoners and landscape facilities. The last one is relevant places for activities, where gym and training grounds are included. Thus, the structure and space arrangement of prison's environment and buildings are very complex. Different space has its own function and feature, which requires the identifying function of color to help prisoners to recognize the functional areas accordingly. Prison's environment color design should not only consider integrity to form a distinctive prison space, but also need to think about the color appearance of each functional area to distinguish the complicated prison environment and to enhance the color recognition of the external and internal environment, which would be convenient to give orientation for prisoners to assemble and evacuate effectively. At the same time, prison environment can also be combined with different regional characteristics or national customs for the formation of a new image of the prison with rich culture system.

\section{CONCLUSION}

The study of penology should focus both on the macro penalty concept as well as middle level of prison system, and the micro research on the penalty technique. Prison building design needs guidance from concept and system, and also 
micro technology. Since the establishment of the People's Republic of China, the domestic research on prison buildings' construction and environment design has not been satisfying due to some subjective and objective factors. But in today's new historical period, prison buildings and environment construction have achieved a major breakthrough. The study on prison building construction should be a combination of architecture and penology, and a good study on prison's environment color design should be of multidisciplinary conformability, which relates to the penology, prison architecture, criminal psychology, environmental metaphysics, art design, chromatics, design psychology and related theories and laws and regulations. Prison's environment color is a color system study, which takes prison environment design as prisoners' transformation as its center. Research and theoretical knowledge above lay a foundation for the prison's environment color design, and effectively guide the prison environment planning and color configuration under a harmonious society. At present, China's prison planning and construction has made a great progress on theory research and practice on the basis of foreign successful cases, but the study of micro prison's environment color design just starts. From now on, scholars, experts and managers of different industries should cooperate with each other and together work for a further study with multidisciplinary conformability. Based on some points of view from the international society and the social situation of China, the prison' environment color design should adhere to the following basic principles. That is to design according to law, to give the priority to practical functions, to have a moderate advanced development and to take the overall situation into consideration. To design according to law is to implement relevant law-making stipulation and spirit in the prison's environment color design, and it shall meet the needs of safety, strong applicability, beauty and so on. To give the priority to practical functions means attention should be paid to the specific function requirements in the prison's environment color design, and security function, transformation function and life function should be taken in full consideration. Having a moderate advanced development requires people to think of the long-term development in the future based on the current situation.

\section{REFERENCES}

[1] Pei Shengxing, Investigation of Humanization Jail Architectural Space. Xi'an: School of Human settlements and Civil Engineering, Xi'an Jiao Tong University, 2007, pp.56-58.

[2] Chu Juntao, Research on Humanized Management of Prison. Beijing: Law School of China University of Political Science and Law, 2009, pp. 32-35.

[3] Wu Zongxian, A Study of Modern Civilized Prisons in China. Beijing: Police Education Press, 1966, pp.303.

[4] Wu Daoyi, Prison Building Environment Color to Correct Criminal Psychology. Kaifeng: Journal of Kaifeng Institute of Education, 2009, pp.48-49.

[5] Dennis Coon, Introduction to Psychology: Gateways to Mind and Behavior. Beijing: China Light Industry Press, 2004, pp.179.

[6] Wu Zongxian, Psychological Correction Techniques for Prisoners in China. Beijing: Beijing Normal University press, 2010, pp.04-07.
[7] Faber Birren, Light, Color and Environment. Beijing: New Times Press, 1988, 103

[8] Richard Webster, Color Magic for Beginners. Xi'an: Xi'an press, 2011, pp.66-70.

[9] Hu Guorong, Research on Color Mode Design of Environment in Hospital. Bejing: Beijing Institute of Fashion Technology, 2012, pp.52-54.

[10] Kim Yoog Sook, Research on Color Mode Design of Environment in Hospital. Bejing: Beijing Institute of Fashion Technology, 2012, pp.54.

[11] Wang Xiaoshan, Contemporary Prison Planning, Design and Construction. Bejing: Law Press, 2010, pp.175-178. 